\title{
İnovasyon ile Küresel Rekabetçilik Düzeyi Arasındaki İlişkide Ekonomik Serbestliğin Düzenleyici Rolü

\author{
(The Moderator Role of Economic Freedom in the Relationship Between Innovation and \\ Global Competitiveness)
}

\author{
Kerem TOKER iD a Ali GÖRENER (iD b \\ a Bezmialem Vakıf Üniversitesi, Sağlık Bilimleri Fakültesi, İstanbul, Türkiye. ktoker@bezmialem.edu.tr \\ b İstanbul Ticaret Üniversitesi, İşletme Fakültesi, İstanbul, Türkiye. agorener@ticaret.edu.tr
}

\begin{tabular}{|c|c|}
\hline MAKALE BİLGİSİ & ÖZET \\
\hline $\begin{array}{l}\text { Anahtar Kelimeler: } \\
\text { Ekonomik Serbestlik }\end{array}$ & $\begin{array}{l}\text { Amaç - Bu araştırmanın amacı, ülke ekonomilerinin inovasyon kabiliyeti ile küresel rekabetçilik } \\
\text { düzeyleri arasındaki ilişkide ekonomik serbestliğin düzenleyici rolünü saptamaktır. }\end{array}$ \\
\hline $\begin{array}{l}\text { Küresel Rekabetçilik } \\
\text { İnovasyon }\end{array}$ & $\begin{array}{l}\text { Yöntem - Araştırma modelini test etmek amacıyla } 2019 \text { yılına ait üç farklı küresel rapordan (Küresel } \\
\text { İnovasyon Endeksi, Ekonomik Serbestlik Endeksi ve Küresel Rekabetçilik Endeksi) elde edilen } \\
\text { veriler analiz edilmiştir. Araştırmaya her üç raporda da verisi bulunan ülkeler dahil edildiği için, } \\
125 \text { ülke araştırmanın kapsamını oluşturmaktadır. Araştırma hipotezini test etmek amacıyla } \\
\text { gerçekleştirilen düzenleyici etki analizlerinde Hayes (2018) tarafından geliştirilen Process Macro } \\
\text { programı ve korelasyon analizlerinde SPSS } 25 \text { istatistik programı kullanılmıştır. }\end{array}$ \\
\hline $\begin{array}{l}2020 \\
\text { Revizyon Tarihi } 2 \text { Eylül } 2020 \\
\text { Kabul Tarihi } 17 \text { Eylül } 2020\end{array}$ & $\begin{array}{l}\text { Bulgular - Regresyon analiz sonuçları, ülkelerin ekonomik serbestlik düzeylerinin, inovasyon ve } \\
\text { küresel rekabetçilik düzeyi arasındaki ilişkide düzenleyicilik rolü olduğunu göstermiştir. Özellikle } \\
\text { inovasyon kabiliyetinin orta düzeyi geçtiği durumlarda eknomik serbestliğin düşük olması } \\
\text { rekabetçlik üzerinde olumlu etkiye neden olmaktadır. }\end{array}$ \\
\hline $\begin{array}{l}\text { Makale Kategorisi: } \\
\text { Araştırma Makalesi }\end{array}$ & $\begin{array}{l}\text { Tartışma - Ülkelerin küresel rekabet gücünü arttırmak için uyguladıkları inovasyon politikalarında, } \\
\text { ekonomik düzenlemelerin ihmal edilmemesi gereken kritik bir unsur olduğunu ortaya } \\
\text { koymaktadır. Küresel işletmelerin ise doğrudan dış yatırım kararlarında aday ülkenin inovasyon } \\
\text { gücü yanında ekonomik düzenlemelerini de göz önünde bulundurmaları önerilmektedir. }\end{array}$ \\
\hline
\end{tabular}

\begin{tabular}{ll}
\hline ARTICLE INFO & ABSTRACT \\
\hline $\begin{array}{l}\text { Keywords: } \\
\text { Economic Freedom }\end{array}$ & $\begin{array}{l}\text { Purpose - This study aims to determine the moderator role of economic freedom in the relationship } \\
\text { between the economies' ability of the country's economies and global competitiveness levels. } \\
\text { Global Competitiveness } \\
\text { Innovation }\end{array}$ \\
$\begin{array}{l}\text { Index, Economic Freedom Index, and Global Competitiveness Index) of 2019 were analyzed to test } \\
\text { the research model. The scope of the research consists of } 125 \text { countries that have data in all three } \\
\text { global reports. The research hypothesis test was carried out with Hayes's (2018) Process Macro } \\
\text { program for the moderator effect analysis and the SPS } 25 \text { statistical program for correlation } \\
\text { analysis. }\end{array}$ \\
$\begin{array}{l}\text { Findings - Regression analysis results showed that countries' economic freedom levels have a } \\
\text { moderator role in the relationship between innovation and global competitiveness. Notably, when } \\
\text { Revised 2 September 2020 } \\
\text { Accepted 17 September 2020 country's innovation capability exceeds the medium level, low economic freedom positively } \\
\text { affects global competitiveness. } \\
\text { Discussion - The results reveal that economic regulations are a critical factor that should not be } \\
\text { neglected in countries' innovation policies to increase their global competitiveness. Accordingly, it } \\
\text { is recommended that global enterprises consider the candidate country's innovation power and } \\
\text { economic regulations in foreign direct investment decisions. }\end{array}$ \\
$\begin{array}{l}\text { Article Classification: } \\
\text { Research Article }\end{array}$
\end{tabular}




\section{Giriş}

21. yüzyılda işletmelerin başarısı bilgiye dayalı ve inovatif bir ekonomi içerisinde yer almalarına dayanmaktadır (Urbancová, 2013). Yeni fikirlerin icadı, geliştirilmesi ve uygulanması olarak tanımlanan inovasyon, işletmelerin uzun vadede hayatta kalmasının temel itici gücü olarak kabul edilmektedir (Khessina vd., 2018; Andersson vd., 2020). Bu nedenle, inovasyon ekonomik büyüme ve ekonomik kalkınmada kritik bir rol üstlenmektedir. Öyle ki, inovasyon, işletmelerin ve girişimcilerin sürekli olarak kaynak verimliliği ve verimlilik artışı sağladıkları Schumpeteryan "yaratıcı yıkım" sürecinin motoru olarak kabul edilmektedir (Cirera ve Muzi, 2020). Bu bağlamda, işletmeler için inovasyonun uygulanabileceği alanlar, yeni veya geliştirilmiş ürün, hizmet ve süreçlerden, organizasyon yapıları, pazarlama yöntemleri veya dış ilişkilere kadar geniş bir yelpazeye sahiptir (Toker vd., 2013; Pikkemaat vd, 2019; Räisänen ve Tuovinen, 2020). Söz konusu geniş uygulama alanı, inovasyonun işletmelerin ve ülke ekonomilerinin sürdürülebilir rekabetçilikleri ile yakından ilişkili olduğunu göstermektedir.

Rekabetçilik, ulusal ve uluslararası pek çok alanda mevcut olan bir durumdur ve genellikle ürün satabilme, fayda ve kaynak sağlama yeteneği olarak tanımlanabilmektedir (García-Sánchez vd., 2019). Rekabetçilik, verimlilik avantajı ve değer avantajından oluşan bir kavramdır. Verimlilik avantajı, bir işletmenin, faaliyetlerini rakiplerinden daha hızl, daha az maliyetli veya daha kaliteli gerçekleştirebilmesi ve bu verimlilik seviyesini sağlayan faktörlerin işletme için bir özyeterlilik haline gelmesidir. Değer avantajı ise, işletmenin müşteriye sağladığı faydanın, müşterinin bu faydayı elde etmek için katlanabileceği maliyeti aşması durumudur. Rekabetçilik, yeni pazarları ele geçirme, diğer aktörleri geride bırakma, yatırım çekme ve büyüme yeteneğini belirlemektedir (Falciola vd., 2020). Eğer rakipler müşteriye bu değeri sağlayamazsa, değer avantajı elde eden işletme pazar ortalamasının üstünde kâr elde edebilir (McGrat vd., 1996). İnovasyon, verimlilik ve değer avantajı sağlayarak işletmelerin rekabet gücünü arttırmaktadır.

İnovasyonun söz konusu kritik önemine rağmen birçok işletme için inovasyon faaliyetlerinin çoğu, dış kaynaklardan elde edilen bilgi ve teknolojinin benimsenmesine dayanmaktadır. Bu durum, yeni teknoloji üreten işletmelerin ve yüksek teknoloji sektörlerinin toplam istihdamın ve üretimin nispeten küçük bir payını oluşturduğu birçok gelişmiş ekonominin endüstriyel yapılarında dahi görülmektedir (O'Brien, 2020). Buradan hareketle çok sayıda ülke, ekonomik büyümeyi teşvik etmek amacıyla belirli endüstrilerde inovasyonu teşvik eden politikalar ortaya koymaktadır (Menna ve Walsh, 2019). Belirtilen durum, inovasyonun işletmelerin içinde bulundukları çevreyle ilgili bağlamsal bir süreç olduğunu göstermektedir. Kamusal ve özel işletmeler içinde bulundukları ekonomik bağlamdan dinamik olarak etkilenerek birlikte evrimsel ve yerel bir inovasyon süreci oluşturmaktadır (Trunfio ve Campana, 2019). Bu bağlamda, bir ekonomik sistemin inovasyon yetenek ve kapasitesi ile küresel rekabetçi avantaj yaratması beklenmektedir. Ancak bu iki değişken arasındaki ilişkinin gücü bütün ülke ekonomileri için aynı mıdır yoksa bu ilişkiyi belirleyen düzenleyici faktörler var midır?

İfade edilen araştırma sorusu çerçevesinde, küresel ekonomide ülkelerin ekonomik sistemlerinin serbestleşme düzeylerinin birbirlerinden farklılaştı̆̆ı görülmektedir. Örneğin, Ekonomik Serbestlik Endeksi'ne (IEF, 2019) göre, Singapur, ekonomik serbestlik düzeyi en yüksek ülkelerden biri olmakla birlikte, Belçika orta, Hindistan ise düşük dereceye sahiptir. Farklı ekonomik serbestlik derecelerine sahip ülkelerde, inovasyon - küresel rekabetçilik ilişkileri de farklılaşmakta mıdır? Bu soru araştırmanın temel problemini oluşturmaktadır. Belirtilen problem doğrultusunda, ülkelerin ekonomik serbestlik düzeyinin, inovasyon - küresel rekabetçilik arasındaki ilişkide düzenleyici rolünü incelemek amaçlanmıştır. Araştırma sonuçlarının, ülke ekonomilerinin birer alt-sistemi olan işletmelerin, uluslararasılaşma stratejilerinde, incelenen değişkenler arasındaki ilişkileri dikkate alarak daha etkin karar vermelerine yardımcı olması beklenmektedir.

\section{Araştırma Hipotezi ve Modeli}

Rekabetçilik konusundaki akademik literatürün hâla gelişmekte olduğu görülmektedir (Ustaömer ve Şengür, 2018; Falciola vd., 2020). Bu çerçevede, bir ülkenin rekabetçilik düzeyini arttıran değişkenler üzerine mikro ve makro seviyede birçok farklı araştırma yapılmaktadır. Araştırmaların çoğunlukla inovasyon-rekabetçilik üzerine, ilişkinin yönünü ve gücünü tespit etmeye yönelik olduğu görülmektedir. Ciocanela ve Pavelescua (2015), Avrupa Birliği (AB) kapsamında yaptıkları araştırmada inovasyonun AB ülkelerinin rekabetçiliği üzerinde pozitif etkisinin olduğunu tespit etmiştir. Zhoa ve Sun (2016), Çin işletmeleri üzerine gerçekleştirdikleri araştırmada, işletmelerin inovasyon faaliyetlerinin işletmelerin rekabetçilik düzeylerini 
pozitif yönde etkilediğini saptamıştır. Gao ve arkadaşları (2020) ise, yine Çin'de faaliyette bulunan işletmeler üzerinde gerçekleştirdikleri araştırmalarında, önceki araştırmalardan farklı olarak inovasyonun rekabetçilik üzerindeki etkisinde hükümet desteğinin düzenleyici rolünü incelemiş ve poziitif etki bulmuştur. Bu araştırmalar işletmeler için verimlilik ve değer avantajı yaratabilecekleri bir ekosistemin en önemli bileşenlerinden birinin inovasyon olduğunu göstermektedir.

Söz konusu araştırmacıların ülke ya da bölge bazında incelemeler yaptıkları görülmektedir. Bunun yanı sıra, ekonomik serbestlik değişkenini araştırma modellerine dahil etmedikleri, böylece işletmelerin faaliyette bulunduğu ekonomilerin yapısal özellikkerini ihmâl ettikleri görülmektedir. Bu durum ilgili literatürde önemli bir boşluk yaratmaktadır. Yapılan açıklamalar ve bağlam doğrultusunda, bu araştırmanın temel amacı, ekonomik bağlamın inovasyon ve rekabetçilik arasındaki ilişki üzerinde düzenleyici bir etkisinin olup olmadığını saptayarak, söz konusu boşluğun doldurulmasına katkı sunmaktır. Bu amaçla geliştirilen araştırma hipotezi şu şekilde ifade edilmiştir:

H1: İnovasyon ile küresel rekabetçilik düzeyi arasındaki ilişkide ekonomik serbestlĭğin düzenleyici etkisi vardır.

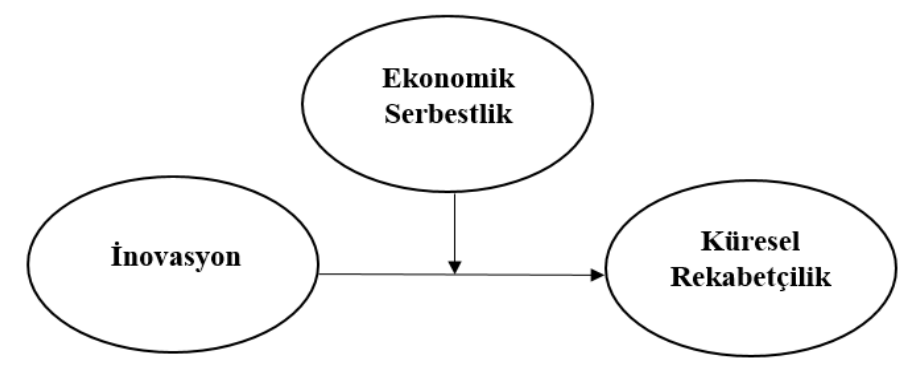

Şekil 1. Kavramsal Araştırma Modeli

H1 hipotezi doğrultusunda geliştirilen araştırmanın kavramsal modeli Şekil 1'de gösterilmektedir.

\section{Yöntem ve Ölçme Araçları}

Araştırma modelini test etmek amacıyla 2019 yılına ait üç farklı küresel rapordan (Küresel İnovasyon Endeksi, Ekonomik Serbestlik Endeksi ve Küresel Rekabetçilik Endeksi) elde edilen veriler analiz edilmiştir. Araştırmaya her üç raporda da verisi bulunan ülkeler dahil edildiği için, 125 ülke araştırmanın kapsamını oluşturmaktadır. Literatürde inovasyon ve rekabetçilik ilişkisinin incelendiği, ikincil verileri kullanarak yapılan farklı çalışmalar da mevcuttur (Rodionova, 2013; Fonseca ve Lima 2015; Petrakis vd., 2015; Zhao ve Sun, 2016; Ivanová ve Čepel, 2018; Feldman vd., 2019; Veselica, 2019).

Araştırma hipotezini test etmek amacıyla gerçekleştirilen düzenleyici etki analizlerinde Hayes (2018) tarafından geliştirilen Process Macro programı ve korelasyon analizlerinde SPSS 25 istatistik programı kullanılmıştır.

Küresel İnovasyon Endeksi: Araştırma modelinde yer alan inovasyon ile ilgili veriler Küresel İnovasyon Endeksi'nden (GII, 2019) elde edilmiştir. Küresel İnovasyon Endeksi'nin 12. baskısı, Cornell Üniversitesi, Institut Européen D'administration Des Affaires (INSEAD) ve Birleşmiş Milletler'in uzmanlaşmış bir ajansı olan Dünya Fikri Mülkiyet Örgütü (World Intellectual Property Organization / WIPO) tarafından ortak olarak yayınlanmıştır. Küresel İnovasyon Endeksi, inovasyon odaklı ekonomik büyümenin çok boyutlu yönleri hakkında genel kabul görmüş bir içgörü kaynağıdır. 2019'da 129 ülke için 80 ayrıntılı metrik sağlayan endeks, bir ekonominin inovasyon performansını ölçmek için önde gelen referanslardan biri haline gelmiştir. 2019'da 12. kez yayınlanan Küresel İnovasyon Endeksi, kamu-özel sektör diyalogunu kolaylaştırabilecek ve politika yapıcıların, iş liderlerinin ve diğer paydaşların inovasyon ilerlemesini yıllık olarak değerlendirebilecekleri değerli bir kıyaslama aracına dönüşmüştür. Küresel İnovasyon Endeksi raporunun temelinde dünya ekonomilerinin inovasyon yetenekleri ve bu konuda ürettikleri sonuçlar yer almaktadır. Son yıllarda endeks kendini inovasyon konusunda öncü bir referans olarak belirlemiştir. İnovasyonun ardındaki insani yönleri daha ayrıntılı olarak anlamak, ekonomik kalkınmayı ve daha zengin inovasyon eğilimli bölgeleri yerel olarak geliştirmeye yardımcı olan politikaların tasarımı için gereklidir. Bu nedenle, ekonomik büyümenin ve refahın itici gücü olarak inovasyonun kilit rolünü ve gelişmiş ve gelişmekte olan ekonomiler için geçerli geniş bir yatay inovasyon vizyonuna duyulan ihtiyacı kabul eden endeks, araştırma ve gelişim düzeyi gibi geleneksel 
inovasyon ölçülerinin ötesine geçen göstergeler içermektedir (GII, 2019). Araştırma modelinde yer alan düzenleyici değişkenle ilgili veriler ise, Ekonomik Serbestlik Endeksi'nden (2019) elde edilmiştir.

Ekonomik Serbestlik Endeksi: Ekonomik serbestlik, her insanın kendi emeğini ve mülkünü kontrol etme temel hakkını ifade etmektedir. Ekonomik açıdan serbest bir toplumda, bireyler istedikleri meslekte istedikleri gibi çalışmak, üretmek, tüketmek ve yatırım yapmakta özgürdürler. Ayrıca, ekonomik serbestliğin yüksek olduğu ülkelerde hükümetler, emeğin, sermayenin ve malların serbestçe hareket etmesine izin verir ve ekonomik serbestliği korumak ve sürdürmek için gerekli olanın ötesinde zorlamalardan kaçınırlar. Heritage Foundation tarafından yayınlanan yıllık bir kılavuz olan Ekonomik Serbestlik Endeksi'nde ekonomik özgürlük, refah ve fırsatlardaki ilerlemeler yirmi yılı aşkın süredir izlenmektedir. 186 ülkenin yer aldığı endeks, mülkiyet haklarından finansal özgürlüğe kadar 12 metriği kapsamaktadır (IEF, 2019). Araştırma modelinin bağımlı değişkenini oluşturan küresel rekabetçilik ile ilgili veriler ise Küresel Rekabetçilik Endeksi'nden (2019) sağlanmıştır.

Küresel Rekabetçilik Endeksi: Dünya Ekonomik Forumu tarafından ilk defa 1979 yılında yayınlanan Küresel Rekabetçilik Endeksi, politika yapıcıların kısa vadeli faaliyetlerin ötesine bakmaları ve ekonomik üretkenliği belirleyen tüm faktörlere karşı ilerlemelerini değerlendirmeleri için yıllık bazda bir ölçüttür. Küresel Rekabetçilik Endeksi'nde 12 metrik yer almaktadır. Bu metrikler; kurumlar, altyapı; bilgi ve iletişim teknolojilerinin benimsenmesi, makroekonomik istikrar, sağlık, beceriler, ürün pazarı, işgücü piyasası, finansal sistem, pazar büyüklüğü, iş dinamizmi ve inovasyon yeteneğidir. Endeks, dünya ekonomisinin \%99'unu oluşturan 141 ülkeyi kapsamakta ve ülke ekonomilerinin zaman içindeki ilerlemesinin izlenmesine olanak tanımaktadır. Bu yaklaşım, rekabet gücünün ülkeler arasında sıfır toplamlı bir oyun olmadığını, tüm ülkeler için erişilebilir olduğunu vurgulamaktadır (GCR, 2019).

125 ülkenin 2019 yılına ait her üç endekse ait puanları tasnif edilerek oluşturulan sıralamalar Ek-1'de gösterilmiştir.

\section{Bulgular}

Değişkenler arasındaki ilişkileri saptamak amacıyla korelesyon analizi gerçekleştirilmiştir. Tablo 1'de inovasyon, ekonomik serbetslik ve küresel rekabetçilik arasındaki ilişkiler gösterilmektedir.

Tablo 1. İnovasyon, Ekonomik Serbestlik ve Küresel Rekabetçilik Arasındaki İlişkiyi Gösteren Korelasyon Katsayıları

\begin{tabular}{lcccc}
\hline Değişkenler & $\mathbf{N}$ & $\mathbf{1}$ & $\mathbf{2}$ & $\mathbf{3}$ \\
\hline 1. İnovasyon & 125 & 1 & $0,747^{* * *}$ & $0,929^{* * *}$ \\
\hline 2. Ekonomik Serbestlik & 125 & & 1 & $0,797^{* * *}$ \\
\hline 3. Küresel Rekabetçilik & 125 & & & 1 \\
\hline$* * * \mathrm{p}<0,001$ & & & &
\end{tabular}

Tablo 1'de görüldüğü gibi inovasyonla küresel rekabetçilik arasındaki \%92,9 oranında pozitif yönde ve çok güçlü bir ilişki vardır. Benzer şekilde, inovasyon ile ekonomik serbestlik arasında da \%74,7 oranında pozitif yönde ve güçlü bir ilişki olduğu görülmektedir. Korelasyon analizinin ardından, araştırma hipotezini test etmek amacıyla ekonomik serbestliğin, inovasyon ve küresel rekabetçilik arasındaki ilişkideki düzenleyicilik rolü test edilmiştir. Elde edilen sonuçlar, Tablo 2'de gösterilmiştir.

Tablo 2'de yer alan bulgular incelendiğinde inovasyon ve ekonomik serbestliğin birlikte rekabetçiliğin $\% 89,4^{\prime}$ ünü $\left(\mathrm{R}^{2}=0,894\right)$ açıkladığı görülmektedir. Bununla birlikte inovasyonun $(b=0,796 ; p<0,004)$ ve ekonomik serbestliğin $(b=0,228 ; \mathbf{p}<0,001)$ rekabetçilik üzerindeki etkisi anlamlıdır. Modelde düzenleyici etki olup olmadığını anlamak için ise, etkileşimsel etkinin anlamlı olup olmadığı kontrol edilmelidir (Gürbüz, 2019). Tablo 1'deki etkileşimsel etkinin $b$ değeri anlamlıdır. $(b=-0,089$, \%95 SH $[-0,148 ;-0,293], \mathbf{t}=-2,951 ; p<0,01)$. Elde edilen sonuçlara göre ekonomik serbestliğin düzenleyici etkiye sahip olduğu görülmektedir. Bu doğrultuda araştırmanın ana hipotezi olan $\mathrm{H}_{1}$ hipotezi kabul edilmiştir. 
K. Toker - A. Görener 12/3 (2020) 2996-3007

Tablo 2. Ekonomik Serbestliğin Düzenleyici Etkisini Gösteren Regresyon Analiz Sonuçları

\begin{tabular}{lccc}
\hline \multicolumn{1}{c}{ Değişkenler } & $\boldsymbol{b}$ & S.H. & $\boldsymbol{t}$ \\
\hline Sabit & $\begin{array}{c}0,066 \\
{[-0,007 ; 0,139]}\end{array}$ & 0,036 & 1,786 \\
\hline İnovasyon $(X)$ & $\begin{array}{c}0,796^{* * *} \\
{[0,704 ; 0,889]}\end{array}$ & 0,046 & 17,073 \\
\hline Ekonomik Serbestlik $(W)$ & $\begin{array}{c}0,228^{* * *} \\
{[0,141 ; 0,316]}\end{array}$ & 0,044 & 5,155 \\
\hline Etkileşimsel Etki $(X . W)$ & $\begin{array}{c}-0,089 * * \\
{[-0,148 ;-0,293]}\end{array}$ & 0,302 & $-2,951$ \\
\hline
\end{tabular}

*** $\mathrm{p}<0,001 ; * * \mathrm{p}<0,01 ; \mathrm{R}=0,945 ; \mathrm{R}^{2}=0,894 ; \mathrm{R}^{2} \mathrm{Chng}=0,007$; S.H.: Standart Hata; Parantez içindeki değerler güven aralıklarıdır. Standardize edilmemiş beta katsayıları (b) raporlanmıştır.

Bununla birlikte düzenleyici etkinin nasıl olduğunu anlamak amacıyla, Tablo 3'te eğim analizi (slope) sonuçları verilmiştir. Düzenleyici değişken olan ekonomik serbestliğin düşük $(-0,942)$, orta $(-0,025)$ ve yüksek $(1,057)$ olduğu durumlarda inovasyonun rekabetçilik üzerinde etkisinin anlamlı olup olmadığını gösteren b katsayıları incelediğinde her üç katsayının da anlamlı $(p<0,001)$ olduğu saptanmıştır.

Tablo 3. Ekonomik Serbestliğin Farklı Değerlerine Göre Durumsal Etkiler

\begin{tabular}{ccccc}
\hline Düzey & $\begin{array}{c}\text { Ekonomik } \\
\text { Serbestlik }\end{array}$ & $\boldsymbol{b}$ & S.H. & $\boldsymbol{t}$ \\
\hline Düşük & $-0,942$ &, $880^{* * *}$ &, 0617 & 14,271 \\
\hline Orta & $-0,025$ &, $799^{* * *}$ &, 0469 & 17,032 \\
\hline Yüksek & 1,057 &, $702^{* * *}$ &, 0477 & 14,731 \\
\hline
\end{tabular}

$* * * \mathrm{p}<0,001$

Şekil 2'de gösterilen eğim analizi sonuçları grafiksel olarak betimlenerek incelendiğinde ise, ekonomik serbestlik düşük düzeyde olduğunda $(-0,942)$ inovasyon ve küresel rekabetçilik arasındaki ilişki anlamlıdır $(b=0,880 ; \mathrm{t}=14,271 ; p<0,001)$. Ekonomik serbestlik orta düzeyde olduğunda $(-0,025)$ inovasyon ve küresel rekabetçilik arasındaki ilişki anlamlıdır $(b=0,799 ; \mathrm{t}=17,032 ; p<0,001)$. Son olarak, ekonomik serbestlik yüksek düzeyde olduğunda $(1,057)$ inovasyon ve küresel rekabetçilik arasındaki ilişki anlamlıdır $(b=0,702$; $\mathbf{t}=14,731$; $p<0,001)$.

Elde edilen analiz sonuçlarında, ülkelerin ekonomik serbestlik dereceleri, inovasyon düzeyi düşük ve orta düzeyde iken benzer eğimleri göstermektedir. Ancak inovasyon düzeyi orta seviyeyi geçtikten sonraki aşamalarda düşük ekonomik serbestliğin daha yüksek düzenleyici etkiye sahip olduğu görülmektedir. 


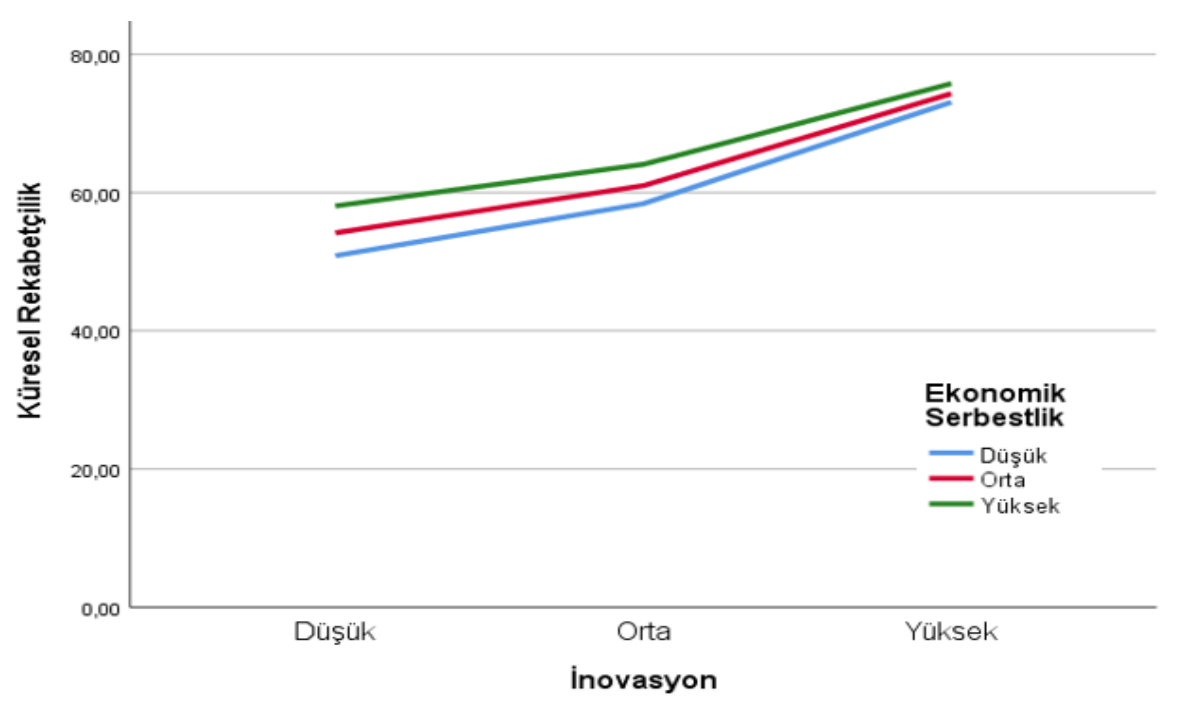

Şekil 2. Ekonomik Serbestliğin Düzenleyici Etkilerinin Grafiksel Gösterimi

\section{Sonuç ve Tartışma}

İşletmeler uluslararası pazarlarda doğrudan yatırım kararlarını verirken kendilerine en fazla rekabet avantajı sağlayacak ülkeyi tercih etmek istemektedirler. Belirtilen tercih, işletmenin ekonomik sürdürülebilirliğini etkileyen stratejik bir karardır. Bu nedenle işletmeler yatırım risklerini en aza indirgeyecek seçenekler üzerinde seçim yapmalıdır. Bu çerçevede, yatırım yapılacak ülkenin inovasyon kabiliyeti, bir başka deyişle inovasyonu gerçekleştirebilecek sosyal, beşeri ve kurumsal altyapılar önem arz etmektedir. Ülkelerin inovasyon kapasitesi ve buna bağlı küresel rekabetçilik avantantajları dışarıdan doğrudan yatırım çekmelerinde temel stratejik unsurlar olarak görülmektedir. Ancak buradan gözden kaçırılmaması gereken bir başka unsur ise, yatırım yapılacak ülkenin ekonomik serbestlik düzeyidir.

Araştırmanın temel problemi yukarıda bahsedilen değişkenlerin birbirleriyle olan ilişkilerinin nasıl olabileceği sorusundan hareketle ortaya çıkmıştır. İnovasyonun rekabetçilik üzerinde etkisi uzun zamandır bilinen bir olgu iken (McGrath vd., 1996; Coccia, 2017; Battisti vd., 2019); ekonomik serbestlik bu etkinin çerçevesini belirleyip, sınırlayan bir düzenleyici değişken olabilir mi? Bu amaçla 2019 yılında yayınlanmış Küresel İnovasyon Endeksi, Ekonomik Serbestlik Endeksi ve Küresel Rekabetçilik Endeksi'nden elde edilen 125 ülkeye ait veriler (Bkz: Ek-1) ile gerçekleştirilen regresyon analizi sonucunda, ekonomik serbestliğin inovasyon ile rekabetçilik arasındaki ilişkide düzenleyicilik etkisi saptanmıştır.

Regresyon analiz sonuçları çerçevesinde gerçekleştirilen eğim analizinde, ekonomik serbestliğin farklı değerler alması durumunda inovasyonun rekabetçilik üzerindeki etkisinin gücü incelenmiştir. Elde edilen bulgular, inovasyon endeks değeri orta düzeye kadar olan ekonomilerde, düşük, orta ve yüksek ekonomik serbestlik düzeylerinin benzer düzeyde düzenleyici etki yarattığını göstermiştir. Bir başka deyişle, inovasyonun düzeyinin düşük olduğu ülkelerde, ekonomik düzenlemeler arasındaki farklılıklar ülkelerin rekabetçiliği üzerinde belirleyici olmamaktadır. Ancak bir ülkenin inovasyon düzeyi orta dereceyi geçtikten sonra, rekabetçilik üzerinde yaratılan etkide düşük ekonomik serbestliğin daha yüksek düzenleyici etki gösterdiği bulunmuştur. Bu sonuç, ülkelerin inovasyon kabiliyetleri arttıkça, işletmelerin ve diğer paydaşların daha fazla ekonomik düzenlemeye ihtiyaç duyduğunu göstermektedir.

Elde edilen sonuçlar, literatürde daha önce yapılan araştırmalar çerçevesinde incelendiğinde; Zhao ve Sun (2016), kurumsal inovasyon ve kurumsal rekabetçilik üzerine Çin'de gerçekleştirdikleri araştırmada, kurumsal inovasyonun kurumsal rekabetçilik üzerinde güçlü etkisinin olduğunu saptamışlardır. Ancak yazarlar, bu çalışmanın kavramsal modelinden farklı olarak çevresel düzenlemelerin kurumsal inovasyon üzerindeki etkisini inceleyip, bu etkinin zayıf olduğunu tespit etmişlerdir. Benzer şekilde, Veselica'nın (2019) gerçekleştirmiş olduğu bir başka çalışmada, Hırvatistan, Avrupa Birliği ve Adriyatik Hırvatistan Bölgesi'nde ayrı ayrı dijital inovasyon ve rekabetçilik arasındaki ilişki incelenmiş ve değişkenler arasında güçlü bağlantılar saptanmıştır. Bu doğrultuda, araştırmanın bağımsız (inovasyon) ve bağımlı (küresel rekabetçilik) değişkenleri 
arasındaki ilişki literatürdeki benzer çalışmalarla örtüşmektedir. Fakat söz konusu her iki araştırmada da inovasyonun rekabetçilik üzerindeki etkisinde düzenleyici rol üstlenecek bir değişken incelenmemiştir. Bununla birlikte, her iki değişken arasındaki ilişkiyi inceleyen Gao ve arkadaşlarının (2020) çalışmasında, iki değişken arasındaki ilişkide hükümet desteğinin pozitif ve orta düzeyde düzenleyici rolü tespit edilmiştir. Yazarların elde ettiği sonuçlar, bu çalışmanın sonuçlarını desteklemektedir. Ancak bu çalışmanın sonuçları, hükümetin düzenleyici rolünün, hangi inovasyon düzeylerinde nasıl olması gerektiğini belirleyerek ilgili alana özgün bir katkı sağlamaktadır.

Sonuçlar uluslararası işletmecilik perspektifinden incelendiğinde, işletmelerin uluslararasılaşma aşamasındaki stratejik karar süreçlerine olumlu katkı sağlayabileceği ifade edilebilir. İşletmelerin uluslararasılaşma stratejileri ihracat, ortaklık ya da doğrudan yatırım şeklinde olabilmektedir (Guillotin ve Mangematin, 2015; Sim ve Pandian, 2007). Bu stratejilerden en düşük riskli olan ihracat iken, doğrudan yatırım en riskli stratejiyi oluşturmaktadır (Tsai ve Eisingerich, 2010). Belirtilen doğrultuda işletmeler girişimde bulunacakları dış pazarların yapısal özelliklerini etkili bir şekilde analiz ederek, işletmenin amaçlarına ulaşmasına yardımcı olacak en uygun stratejiyi seçmelidir (Schmid, 2018). Özellikle seçilecek strateji doğrudan dış yatırım olduğunda, karar probleminin maliyeti ve riski yükselmektedir.

Murtinu ve Scalera'ya (2016) göre doğrudan yatırım yoluyla yapılan uluslararası yatırımlar, kaynak taahhüdü, risk, performans ve kontrol açısından önemli etkileri olabilecek alternatif uluslararasılaşma stratejisidir. Elde edilen bulgular çerçevesinde doğrudan dış yatırım yapmak isteyen işletmelere, stratejik karar süreçlerinde ülkelerin inovasyon seviyelerini ve ekonomik serbestlik düzeylerini göz önünde bulundurmaları önerilmektedir. Öyle ki, inovasyon düzeyi arttıkça ülkelerin ve işletmelerin rekabetçiliğinin de artması için işletmeler ekonomi yönetiminde patent, hukuki koruma, kurumsal teşvikler gibi birtakım düzenlemelere ihtiyaç duymaktadır. Bu nedenle, inovasyonun ortaya çıkabilmesi için daha serbest girişimcilik ekosistemlerine ihtiyaç duyulurken, inovasyon kabiliyeti ve uygulamaları belirli bir olgunluğa eriştikten sonra ekonomik düzenlemelerin varlığı, işletmelerin rekabetçi performansını olumlu yönde etkilemektedir. Bu nedenle inovatif işletmelere, yasal haklarını koruma altına alabilmeleri için ekonomik serbestliğin kısmen düşük olduğu Almanya, Norveç, Japonya gibi ülkelere yatırım yapmaları önerilirken, yenilikçi ekosistemlerin sunduğu avantajlardan yararlanarak inovatif bir işletme yapısına dönüşmek isteyen işletmelere Singapur, Hong Kong, İsviçre gibi ekonomik serbestliğin yüksek olduğu ülkelere yatırım yapmaları önerilmektedir. Uluslararasılaşma sürecindeki işletmeler kendi amaçlarına en uygun rekabetçi avantajı, bu karar stratejisi ile sağlayabilmesi beklenmektedir.

$\mathrm{Bu}$ araştırma ile uluslararası işletmecilik uygulamalarında, inovasyonun rekabetçi avantaj yaratması için ekonomik düzenlemelere ihtiyaç duyulduğu saptanmıştır. Bununla birlikte araştırmanın birtakım kısıtları söz konusudur. Araştırma modelinin testi, modelde yer alan değişkenlerin sadece 2019 yllına ait verileri analiz edilerek gerçekleştirilmiştir. Bu zaman kapsamı, araştırma kısıtlarından ilkini oluşturmaktadır. İleride yapılacak araştırmalarda birden fazla yılın verileri bir arada kullanılarak panel veri analizi yapılabilir. Bir başka kısıt ise, araştırmada küresel ölçekte verilerin analizi yapılarak, bölgesel farklılıkların dikkate alınmamasıdır. Bu nedenle, bölgesel bazda endeksler oluşturularak karşılaştırmalı model analizler sayesinde daha ayrıntılı sonuçlar saptanabilir. Ayrıca, araştırma modeline ülkelerin insanı gelişmişlik düzeyleri gibi değişkenler eklenerek, farklı ve anlamlı ilişkilere ait analizler yapılabilir.

\section{Kaynaklar}

Andersson, M., Moen, O., \& Brett, P. O. (2020). The organizational climate for psychological safety: Associations with SMEs' innovation capabilities and innovation performance. Journal of Engineering and Technology Management, 55: 1-13.

Battisti, E., Miglietta, N., Nirino, N., \& Diaz, M. V. (2019). Value creation, innovation practice, and competitive advantage. European Journal of Innovation Management, 22, 1-18.

Ciocanel, A. B., \& Pavelescu, F. M. (2015). Innovation and competitiveness in European context. Procedia Economics and Finance, 32(15), 728-737.

Cirera, X., \& Muzi, S. (2020). Measuring innovation using firm-level surveys: Evidence from developing countries. Research Policy, 49(3): 1-19. 
Coccia, M. (2017). Sources of technological innovation: Radical and incremental innovation problem-driven to support competitive advantage of firms. Technology Analysis \& Strategic Management, 29(9), 1048-1061.

Falciola, J., Jansen, M., \& Rollo, V. (2020). Defining firm competitiveness: A multidimensional framework. World Development, 129, 104857: 1-14.

Feldman, P. R., Jacomossi, R. R., Barrichello, A., \& Morano, R. S. (2019). The relationship between Innovation and Global Competitiveness: The mediating role of Management Practices evaluated by Structural Equation Modeling. Review of Business Management, 21(2), 195-212.

Fonseca, L. M., \& Lima, V. M. (2015). Countries three wise men: Sustainability, Innovation, and Competitiveness. Journal of Industrial Engineering and Management, 8(4), 1288-1302.

Gao, A., Lin, Y., \& Zhou, Y. (2020). Does an Innovative Climate Help to Sustain Competitiveness? The Moderating Effect of Government Support and Market Competition. Sustainability, 12(5), 2029.

García-Sánchez, A., Siles, D., \& Vázquez-Méndez, M. D. M. (2019). Competitiveness and innovation: effects on prosperity. Anatolia, 30(2), 200-213.

GCR. (2019). The Global Competitiveness Report. http://www3.weforum.org /docs/WEF TheGlobalCompetitivenessReport2019.pdf Erişim Tarihi: 05.02.2020

GII. (2019). The Global Innovation Index. https://www.globalinnovationindex.org/home Erişim Tarihi: 22.01.2020

Guillotin, B., \& Mangematin, V. (2015). Internationalization strategies of business schools: how flat is the world?. Thunderbird International Business Review, 57(5), 343-357.

Gürbüz, S. (2019). Sosyal bilimlerde aract, düzenleyici ve durumsal etki analizleri. Ankara: Seçkin Akademik ve Mesleki Yayınlar.

Hayes, A. F. (2018). Introduction to mediation, moderation, and conditional process analysis: A regression-based approach. 2nd Edition, Guilford publications.

IEF. (2019). Index of Economic Freedom. https://www.heritage.org/index/ Erişim Tarihi: 05.02.2020.

Ivanová, E., \& Čepel, M. (2018). The impact of innovation performance on the competitiveness of the Visegrad 4 countries. Journal of Competitiveness, 10(1), 54.

Khessina, O. M., Goncalo, J. A., \& Krause, V. (2018). It's time to sober up: The direct costs, side effects and long-term consequences of creativity and innovation. Research in Organizational Behavior, 38, 107-135.

McGrath, R. G., Tsai, M. H., Venkataraman, S., \& MacMillan, I. C. (1996). Innovation, competitive advantage and rent: a model and test. Management Science, 42(3), 389-403.

Menna, A., \& Walsh, P. R. (2019). Assessing environments of commercialization of innovation for SMEs in the global wine industry: A market dynamics approach. Wine Economics and Policy, 8(2), 191-202.

Murtinu, S., \& Scalera, V. G. (2016). Sovereign wealth funds' internationalization strategies: the use of investment vehicles. Journal of International Management, 22(3), 249-264.

O'Brien, K. (2020). Innovation types and the search for new ideas at the fuzzy front end: Where to look and how often?. Journal of Business Research, 107, 13-24.

Petrakis, P. E., Kostis, P. C., \& Valsamis, D. G. (2015). Innovation and competitiveness: Culture as a long-term strategic instrument during the European Great Recession. Journal of Business Research, 68(7), 14361438.

Pikkemaat, B., Peters, M., \& Bichler, B. F. (2019). Innovation research in tourism: Research streams and actions for the future. Journal of Hospitality and Tourism Management, 41: 184-496.

Räisänen, J., \& Tuovinen, T. (2020). Digital innovations in rural micro-enterprises. Journal of Rural Studies, 73, 56-67. 
K. Toker - A. Görener 12/3 (2020) 2996-3007

Rodionova, I. (2013). Competitiveness of countries in the world innovation economy: Central-Eastern Europe and Russia. Quaestiones Geographicae, 32(2), 15-24.

Schmid, S. (2018). Strategies of internationalization: An overview. (in) Internationalization of Business: Cases on Strategy Formulation and Implementation. Cham: Springer International Publishing.

Sim, A. B., \& Pandian, J. R. (2007). An exploratory study of internationalization strategies of Malaysian and Taiwanese firms. International Journal of Emerging Markets, 2(3), 252-273.

Toker, K., Cakirel, Y., \& Cinar, D. (2013). An investigation on a production company via the scope of Mintzberg's adhocratic organization structure. International Journal of Research in Business and Social Science, 2(1): 22-30.

Tsai, H. T., \& Eisingerich, A. B. (2010). Internationalization strategies of emerging markets firms. California Management Review, 53(1), 114-135.

Trunfio, M., \& Campana, S. (2019). Drivers and emerging innovations in knowledge-based destinations: Towards a research agenda. Journal of Destination Marketing \& Management, 14, 1-11.

Urbancova, H. (2013). Competitive advantage achievement through innovation and knowledge. Journal of Competitiveness, 5(1), 82-96.

Ustaömer, T. C., \& Şengür, F. (2018). Türk Havaalanı Sektörünün Uluslararası Rekabetçilik Analizi, Mehmet Akif Ersoy Üniversitesi Sosyal Bilimler Enstitüsü Dergisi, 10(26), 811-831.

Veselica, R. (2019). Linking Innovation and National Competitiveness. Economic and Social Development: Book of Proceedings, 279-287.

Zhao, X., \& Sun, B. (2016). The influence of Chinese environmental regulation on corporation innovation and competitiveness. Journal of Cleaner Production, 112, 1528-1536. 
Ek-1. 125 Ülkenin Küresel İnovasyon Endeksi, Küresel Rekabetçilik Endeksi ve Ekonomik Serbestlik Endeksi Puanlar1*

No Ülke Sıra İnovasyon Sıra Rekabetçilik Sıra Ekonomik Serbestlik

\begin{tabular}{|c|c|c|c|c|c|c|c|}
\hline 1 & Switzerland & 1 & 67,24 & 5 & 82,3 & 4 & 81,9 \\
\hline 2 & Sweden & 2 & 63,65 & 8 & 81,2 & 18 & 75,2 \\
\hline 3 & $\begin{array}{l}\text { United States of } \\
\text { America }\end{array}$ & 3 & 61,73 & 2 & 83,7 & 11 & 76,8 \\
\hline 4 & Netherlands & 4 & 61,44 & 4 & 82,4 & 12 & 76,8 \\
\hline 5 & United Kingdom & 5 & 61,3 & 9 & 81,2 & 7 & 78,9 \\
\hline 6 & Finland & 6 & 59,83 & 11 & 80,2 & 19 & 74,9 \\
\hline 7 & Denmark & 7 & 58,44 & 10 & 81,2 & 13 & 76,7 \\
\hline 8 & Singapore & 8 & 58,37 & 1 & 84,8 & 2 & 89,4 \\
\hline 9 & Germany & 9 & 58,19 & 7 & 81,8 & 23 & 73,5 \\
\hline 10 & Israel & 10 & 57,43 & 18 & 76,7 & 26 & 72,8 \\
\hline 11 & Republic of Korea & 11 & 56,55 & 12 & 79,6 & 28 & 72,3 \\
\hline 12 & Ireland & 12 & 56,1 & 23 & 75,1 & 6 & 80,5 \\
\hline 13 & Hong Kong, China & 13 & 55,54 & 3 & 83,1 & 1 & 90,2 \\
\hline 14 & China & 14 & 54,82 & 27 & 73,9 & 87 & 58,4 \\
\hline 15 & Japan & 15 & 54,68 & 6 & 82,3 & 29 & 72,1 \\
\hline 16 & France & 16 & 54,25 & 14 & 78,8 & 64 & 63,8 \\
\hline 17 & Canada & 17 & 53,88 & 13 & 79,6 & 8 & 77,7 \\
\hline 18 & Luxembourg & 18 & 53,47 & 17 & 77 & 15 & 75,9 \\
\hline 19 & Norway & 19 & 51,87 & 16 & 78,1 & 24 & 73 \\
\hline 20 & Iceland & 20 & 51,53 & 25 & 74,7 & 10 & 77,1 \\
\hline 21 & Austria & 21 & 50,94 & 20 & 76,6 & 30 & 72 \\
\hline 22 & Australia & 22 & 50,34 & 15 & 78,7 & 5 & 80,9 \\
\hline 23 & Belgium & 23 & 50,18 & 21 & 76,4 & 45 & 67,3 \\
\hline 24 & Estonia & 24 & 49,97 & 30 & 70,9 & 14 & 76,6 \\
\hline 25 & New Zealand & 25 & 49,55 & 19 & 76,7 & 3 & 84,4 \\
\hline 26 & Czech Republic & 26 & 49,43 & 31 & 70,9 & 22 & 73,7 \\
\hline 27 & Malta & 27 & 49,01 & 37 & 68,5 & 36 & 68,6 \\
\hline 28 & Cyprus & 28 & 48,34 & 43 & 66,4 & 41 & 68,1 \\
\hline 29 & Spain & 29 & 47,85 & 22 & 75,3 & 52 & 65,7 \\
\hline 30 & Italy & 30 & 46,3 & 29 & 71,5 & 70 & 62,2 \\
\hline 31 & Slovenia & 31 & 45,25 & 34 & 70,2 & 53 & 65,5 \\
\hline 32 & Portugal & 32 & 44,65 & 33 & 70,4 & 56 & 65,3 \\
\hline 33 & Hungary & 33 & 44,51 & 45 & 65,1 & 59 & 65 \\
\hline 34 & Latvia & 34 & 43,23 & 40 & 67 & 33 & 70,4 \\
\hline 35 & Malaysia & 35 & 42,68 & 26 & 74,6 & 21 & 74 \\
\hline 36 & $\begin{array}{l}\text { United Arab } \\
\text { Emirates }\end{array}$ & 36 & 42,17 & 24 & 75 & 9 & 77,6 \\
\hline 37 & Slovakia & 37 & 42,05 & 41 & 66,8 & 60 & 65 \\
\hline 38 & Lithuania & 38 & 41,46 & 38 & 68,4 & 20 & 74,2 \\
\hline 39 & Poland & 39 & 41,31 & 36 & 68,9 & 42 & 67,8 \\
\hline 40 & Bulgaria & 40 & 40,35 & 47 & 64,9 & 35 & 69 \\
\hline
\end{tabular}


K. Toker - A. Görener 12/3 (2020) 2996-3007

\begin{tabular}{|c|c|c|c|c|c|c|c|}
\hline 41 & Greece & 41 & 38,9 & 58 & 62,6 & 91 & 57,7 \\
\hline 42 & Viet Nam & 42 & 38,84 & 66 & 61,5 & 104 & 55,3 \\
\hline 43 & Thailand & 43 & 38,63 & 39 & 68,1 & 40 & 68,3 \\
\hline 44 & Croatia & 44 & 37,82 & 62 & 61,9 & 74 & 61,4 \\
\hline 45 & Montenegro & 45 & 37,7 & 72 & 60,8 & 79 & 60,5 \\
\hline 46 & Russian Federation & 46 & 37,62 & 42 & 66,7 & 85 & 58,9 \\
\hline 47 & Ukraine & 47 & 37,4 & 82 & 57 & 114 & 52,3 \\
\hline 48 & Georgia & 48 & 36,98 & 73 & 60,6 & 16 & 75,9 \\
\hline 49 & Turkey & 49 & 36,95 & 60 & 62,1 & 62 & 64,6 \\
\hline 50 & Romania & 50 & 36,76 & 50 & 64,4 & 37 & 68,6 \\
\hline 51 & Chile & 51 & 36,64 & 32 & 70,5 & 17 & 75,4 \\
\hline 52 & India & 52 & 36,58 & 67 & 61,4 & 106 & 55,2 \\
\hline 53 & Mongolia & 53 & 36,29 & 99 & 52,6 & 102 & 55,4 \\
\hline 54 & Philippines & 54 & 36,18 & 63 & 61,9 & 65 & 63,8 \\
\hline 55 & Costa Rica & 55 & 36,13 & 61 & 62 & 57 & 65,3 \\
\hline 56 & Mexico & 56 & 36,06 & 48 & 64,9 & 61 & 64,7 \\
\hline 57 & Serbia & 57 & 35,71 & 69 & 60,9 & 63 & 63,9 \\
\hline 58 & Republic of Moldova & 58 & 35,52 & 83 & 56,7 & 84 & 59,1 \\
\hline 59 & North Macedonia & 59 & 35,29 & 79 & 57,3 & 31 & 71,1 \\
\hline 60 & Kuwait & 60 & 34,55 & 46 & 65,1 & 77 & 60,8 \\
\hline 61 & $\begin{array}{l}\text { Iran (Islamic } \\
\text { Republic of) }\end{array}$ & 61 & 34,43 & 96 & 53 & 118 & 51,1 \\
\hline 62 & Uruguay & 62 & 34,32 & 53 & 63,5 & 38 & 68,6 \\
\hline 63 & South Africa & 63 & 34,04 & 59 & 62,4 & 88 & 58,3 \\
\hline 64 & Armenia & 64 & 33,98 & 68 & 61,3 & 44 & 67,7 \\
\hline 65 & Qatar & 65 & 33,86 & 28 & 72,9 & 27 & 72,6 \\
\hline 66 & Brazil & 66 & 33,82 & 70 & 60,9 & 116 & 51,9 \\
\hline 67 & Colombia & 67 & 33 & 56 & 62,7 & 46 & 67,3 \\
\hline 68 & Saudi Arabia & 68 & 32,93 & 35 & 70 & 43 & 60,7 \\
\hline 69 & Peru & 69 & 32,93 & 64 & 61,7 & 78 & 67,8 \\
\hline 70 & Tunisia & 70 & 32,83 & 84 & 56,4 & 103 & 55,4 \\
\hline 71 & Brunei Darussalam & 71 & 32,35 & 55 & 62,8 & 58 & 65,1 \\
\hline 72 & Argentina & 72 & 31,95 & 80 & 57,2 & 115 & 52,2 \\
\hline 73 & Morocco & 73 & 31,63 & 74 & 60 & 66 & 62,9 \\
\hline 74 & Panama & 74 & 31,51 & 65 & 61,6 & 47 & 67,2 \\
\hline 75 & $\begin{array}{l}\text { Bosnia and } \\
\text { Herzegovina }\end{array}$ & 75 & 31,41 & 89 & 54,7 & 71 & 61,9 \\
\hline 76 & Kenya & 76 & 31,13 & 92 & 54,1 & 107 & 55,1 \\
\hline 77 & Bahrain & 77 & 31,1 & 44 & 65,4 & 50 & 66,4 \\
\hline 78 & Kazakhstan & 78 & 31,03 & 54 & 62,9 & 54 & 65,4 \\
\hline 79 & Oman & 79 & 30,98 & 52 & 63,6 & 75 & 61 \\
\hline 80 & Jamaica & 80 & 30,8 & 75 & 58,3 & 39 & 68,6 \\
\hline 81 & Mauritius & 81 & 30,61 & 51 & 64,3 & 25 & 73 \\
\hline 82 & Albania & 82 & 30,34 & 78 & 57,6 & 48 & 66,5 \\
\hline 83 & Azerbaijan & 83 & 30,21 & 57 & 62,7 & 55 & 65,4 \\
\hline 84 & Indonesia & 84 & 29,72 & 49 & 64,6 & 51 & 65,8 \\
\hline 85 & Jordan & 85 & 29,61 & 71 & 60,9 & 49 & 66,5 \\
\hline
\end{tabular}


K. Toker - A. Görener 12/3 (2020) 2996-3007

\begin{tabular}{|c|c|c|c|c|c|c|c|}
\hline 86 & Dominican Republic & 86 & 28,56 & 76 & 58,3 & 76 & 61 \\
\hline 87 & Lebanon & 87 & 28,54 & 85 & 56,3 & 119 & 51,1 \\
\hline 88 & Sri Lanka & 88 & 28,45 & 81 & 57,1 & 97 & 56,4 \\
\hline 89 & Kyrgyzstan & 89 & 28,38 & 93 & 54 & 69 & 62,3 \\
\hline 90 & Trinidad and Tobago & 90 & 28,08 & 77 & 58,3 & 95 & 57 \\
\hline 91 & Egypt & 91 & 27,47 & 90 & 54,5 & 112 & 52,5 \\
\hline 92 & Botswana & 92 & 27,43 & 88 & 55,5 & 34 & 69,5 \\
\hline 93 & Rwanda & 93 & 27,38 & 97 & 52,8 & 32 & 71,1 \\
\hline 94 & Paraguay & 94 & 27,09 & 94 & 53,6 & 72 & 61,8 \\
\hline 95 & Senegal & 95 & 26,83 & 109 & 49,7 & 98 & 56,3 \\
\hline 96 & $\begin{array}{l}\text { United Republic of } \\
\text { Tanzania }\end{array}$ & 96 & 26,63 & 112 & 48,2 & 80 & 60,2 \\
\hline 97 & Cambodia & 97 & 26,59 & 102 & 52,1 & 90 & 57,8 \\
\hline 98 & Ecuador & 98 & 26,56 & 87 & 55,7 & 122 & 46,9 \\
\hline 99 & Tajikistan & 99 & 26,43 & 101 & 52,4 & 100 & 55,6 \\
\hline 100 & Namibia & 100 & 25,85 & 91 & 54,5 & 86 & 58,7 \\
\hline 101 & Uganda & 101 & 25,6 & 110 & 48,9 & 82 & 59,7 \\
\hline 102 & Côte d'Ivoire & 102 & 25,55 & 113 & 48,1 & 68 & 62,4 \\
\hline 103 & Honduras & 103 & 25,48 & 98 & 52,7 & 81 & 60,2 \\
\hline 104 & Pakistan & 104 & 25,36 & 107 & 51,4 & 108 & 55 \\
\hline 105 & Ghana & 105 & 25,27 & 108 & 51,2 & 93 & 57,5 \\
\hline 106 & Guatemala & 106 & 25,07 & 95 & 53,5 & 67 & 62,6 \\
\hline 107 & El Salvador & 107 & 24,89 & 100 & 52,6 & 73 & 61,8 \\
\hline 108 & Nepal & 108 & 24,85 & 105 & 51,6 & 109 & 53,8 \\
\hline 109 & $\begin{array}{l}\text { Bolivia (Plurinational } \\
\text { State of) }\end{array}$ & 109 & 24,76 & 104 & 51,8 & 124 & 42,3 \\
\hline 110 & Ethiopia & 110 & 24,16 & 118 & 44,4 & 110 & 53,6 \\
\hline 111 & Mali & 111 & 24,03 & 121 & 43,6 & 89 & 58,1 \\
\hline 112 & Algeria & 112 & 23,98 & 86 & 56,3 & 123 & 46,2 \\
\hline 113 & Nigeria & 113 & 23,93 & 111 & 48,3 & 94 & 57,3 \\
\hline 114 & Cameroon & 114 & 23,9 & 116 & 46 & 113 & 52,4 \\
\hline 115 & Bangladesh & 115 & 23,31 & 103 & 52,1 & 101 & 55,6 \\
\hline 116 & Burkina Faso & 116 & 23,3 & 122 & 43,4 & 83 & 59,4 \\
\hline 117 & Malawi & 117 & 23 & 120 & 43,7 & 117 & 51,4 \\
\hline 118 & Mozambique & 118 & 22,87 & 125 & 38,1 & 121 & 48,6 \\
\hline 119 & Nicaragua & 119 & 22,55 & 106 & 51,5 & 92 & 57,7 \\
\hline 120 & Madagascar & 120 & 22,38 & 123 & 42,9 & 96 & 56,6 \\
\hline 121 & Zimbabwe & 121 & 22,3 & 119 & 44,2 & 125 & 40,4 \\
\hline 122 & Benin & 122 & 20,42 & 117 & 45,8 & 105 & 55,3 \\
\hline 123 & Zambia & 123 & 20,36 & 114 & 46,5 & 111 & 53,6 \\
\hline 124 & Guinea & 124 & 19,5 & 115 & 46,1 & 99 & 55,7 \\
\hline 125 & Burundi & 125 & 17,65 & 124 & 40,3 & 120 & 48,9 \\
\hline
\end{tabular}

*Tablo her üç endeks baz alınarak yazarlar tarafından düzenlenmiştir. 